Vietnam Journal of Mechanics, NCST of Vietnam Vol. 25, 2003, No 1 (26 - 38)

\title{
ON SOME NUMERICAL METHODS FOR SOLVING THE 1-D SAINT-VENANT EQUATIONS OF GENERAL FLOW REGIME Part 2: Verification and application
}

\author{
Nguyen Van Hanh ${ }^{1}$, Nguyen Van DieP ${ }^{2}$ and Ngo Huy Can ${ }^{2}$ \\ 1 Institute for Water Resources Research, 271 Tay son street, Hanoi, Vietnam \\ ${ }^{2}$ Institute of Mechanics, 264 Doi can street, Hanoi, Vietnam
}

\begin{abstract}
In the Part 1 of this paper [1], some numerical methods for solving the 1-D Saint-Venant equations of general flow regime have been described. This Part of the paper presents the results of verification by various test problems, covering all of three flow regimes: sub-, trans-, and super-critical. The results show that the mixed approach (between pointwise and upwind) for source terms is better than the pointwise one and any mathematical transformation of source terms must be careful, since that can lead to nonphysical solutions. The Roe's approximation with the mixed technique for the source terms is used for a preliminary evaluation of the Son $\mathrm{La}$ - Hoa Binh dambreak problem.
\end{abstract}

\section{Verification of the numerical methods by Test-Cases}

To evaluate the general flow simulation capacity and the advantages of every numerical method presented in the Part 1 of this paper some test cases newly developed by European Hydraulic Laboratories [2,3] will be used. The results of testing will be shown in figures (1-14, 16-21).

In these figures the following notations are used:

- $Z_{g t}, Q_{g t}, V_{g t}$ - analytical water level, discharge, velocity

- $Z_{t t}, Q_{t t}, V_{t t}$ - numerical water level, discharge, velocity

- $Z_{b}$ - bed level

- H - Water depth

\subsection{Schemes with the pointwise source term integral}

\subsubsection{Steady flow through a bump}

In this case all 4 schemes are used to calculate the steady flow through a bump in a rectangular channel with a constant width [2]. Depending on the boundary and the initial conditions the flow may be sub-critical, super-critical, trans-critical or at rest. The comparison between numerical and analytical solutions is made.

Channel has a length of $25 \mathrm{~m}$, a width of $1 \mathrm{~m}$. The bed slope is as follows:

$$
Z_{h}(x)=\left\{\begin{array}{cl}
0.2-0.05(x-10)^{2}, & 8 m<x<12 m \\
0, & x \leq 8 m \text { or } x \geq 12 m
\end{array}\right.
$$


The grid has the space increment $\Delta x=0.025 \mathrm{~m}$. The calculated cases are

(1) Water at rest: $Q=0 \mathrm{~m}^{3} / \mathrm{s}, Z_{h \ell}=2 \mathrm{~m}$,

(2) Transcritical flow without shock $Q=1.53 \mathrm{~m}^{3} / \mathrm{s}, Z_{h \ell}=0.66 \mathrm{~m}$,

(3) Transcritical flow with shock $Q=0.18 \mathrm{~m}^{2} / \mathrm{s}, Z_{h \ell}=0.33 \mathrm{~m}$,

(4) Sub-critical flow: $Q=4.42 \mathrm{~m}^{3} / \mathrm{s}, Z_{h \ell}=2 \mathrm{~m}$.

Table 1. Comparison of the convergence time

\begin{tabular}{|c|c|c|c|c|c|}
\hline \multirow[t]{2}{*}{ Methods } & \multicolumn{4}{|c|}{ Convergence time (s) } & \multirow[t]{2}{*}{ Average (s) } \\
\hline & $\begin{array}{c}\text { Water } \\
\text { at } \\
\text { rest }\end{array}$ & $\begin{array}{c}\text { Transcritical } \\
\text { flow without } \\
\text { shock }\end{array}$ & $\begin{array}{c}\text { Transcritical } \\
\text { flow with } \\
\text { shock }\end{array}$ & $\begin{array}{l}\text { Sub- } \\
\text { critical }\end{array}$ & \\
\hline $\begin{array}{l}\text { Lax-Friedrichs } \\
\text { Roe's }\end{array}$ & 46.98 & 45.37 & 94.19 & 83.26 & 67.75 \\
\hline Approximation & 181.03 & 45.33 & 127.25 & 95.75 & 112.34 \\
\hline $\begin{array}{l}\text { Hybrid } \\
\text { Nessyahu- }\end{array}$ & 1440.00 & 1440.00 & 1440.00 & 111.05 & 1107.80 \\
\hline Tedmor & 204.55 & 45.37 & 128.54 & 97.76 & 119.06 \\
\hline
\end{tabular}

According to the results shown in figures (1-4), the accuracy of methods can be presented in the following order: Roe's approximation, Hybrid, Nessyahu-Tedmor, Lax-Friedrichs. At the smooth region of solutions these methods give nearly the same accuracy, but near discontinuities or nonsmooth part of solutions the Roe's approximation and the Hybrid method are better than Nessyahu-Tedmor and LaxFriedrichs methods.

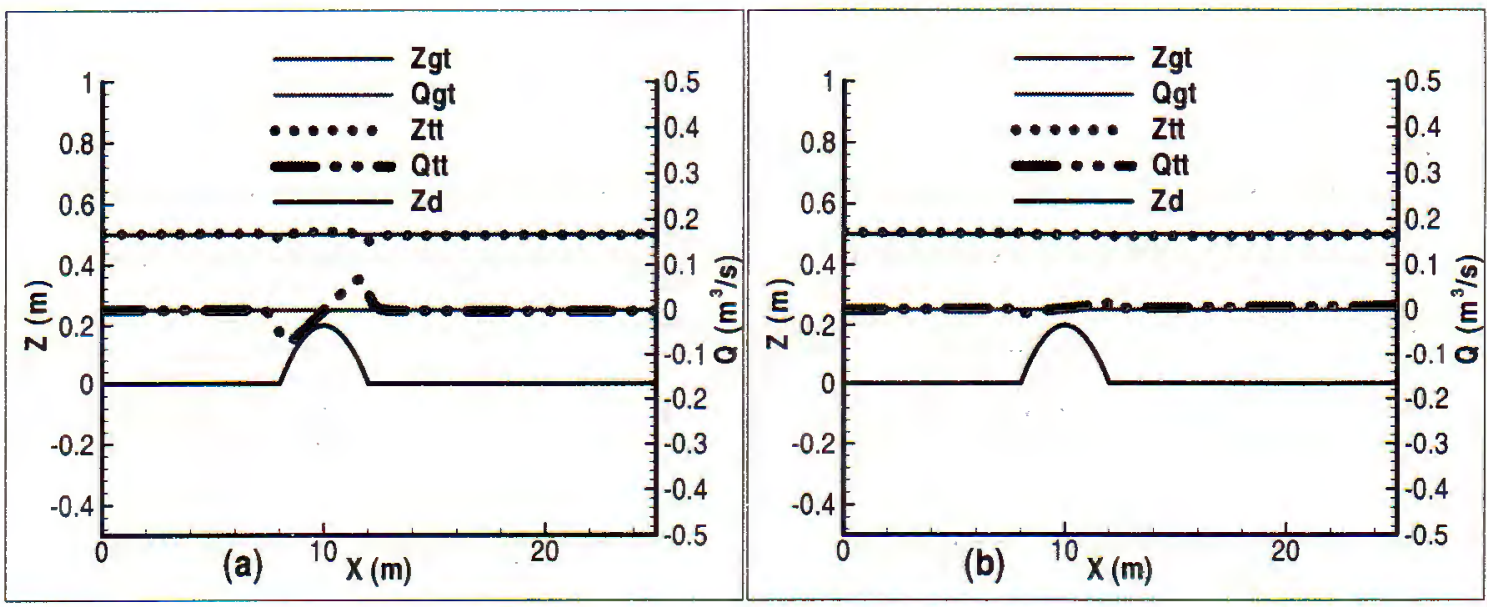

Fig. 1. Water at rest. (a) The Lax-Friedrichs and (b) the Roe's approximation methods 

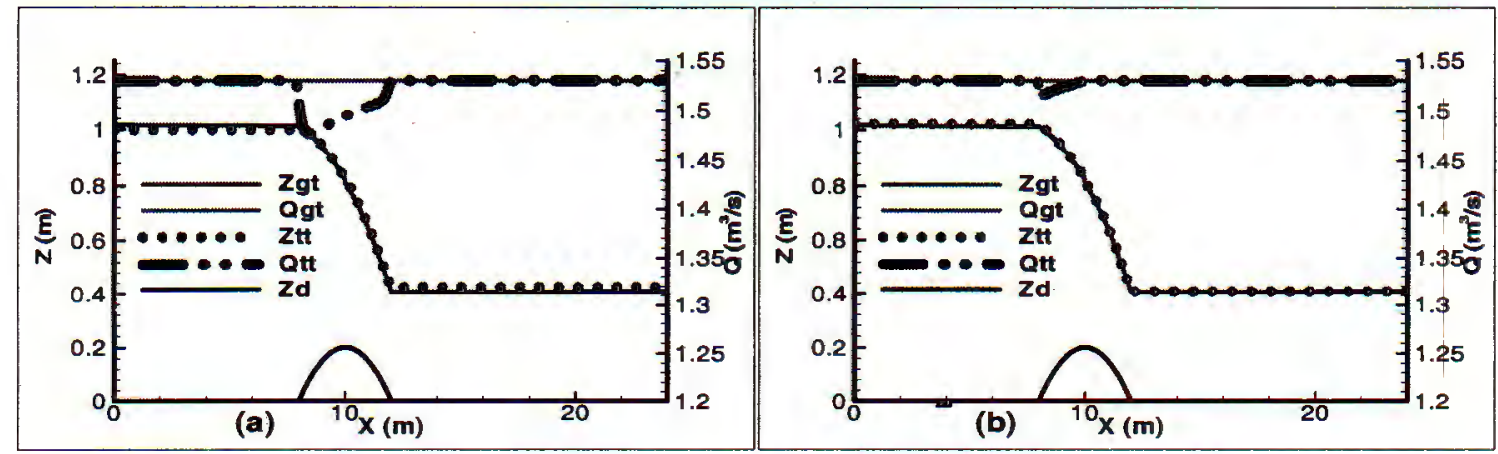

Fig. 2. Transcritical flow without shock.

(a) The Lax-Friedrichs and (b) the Roe's approximation methods
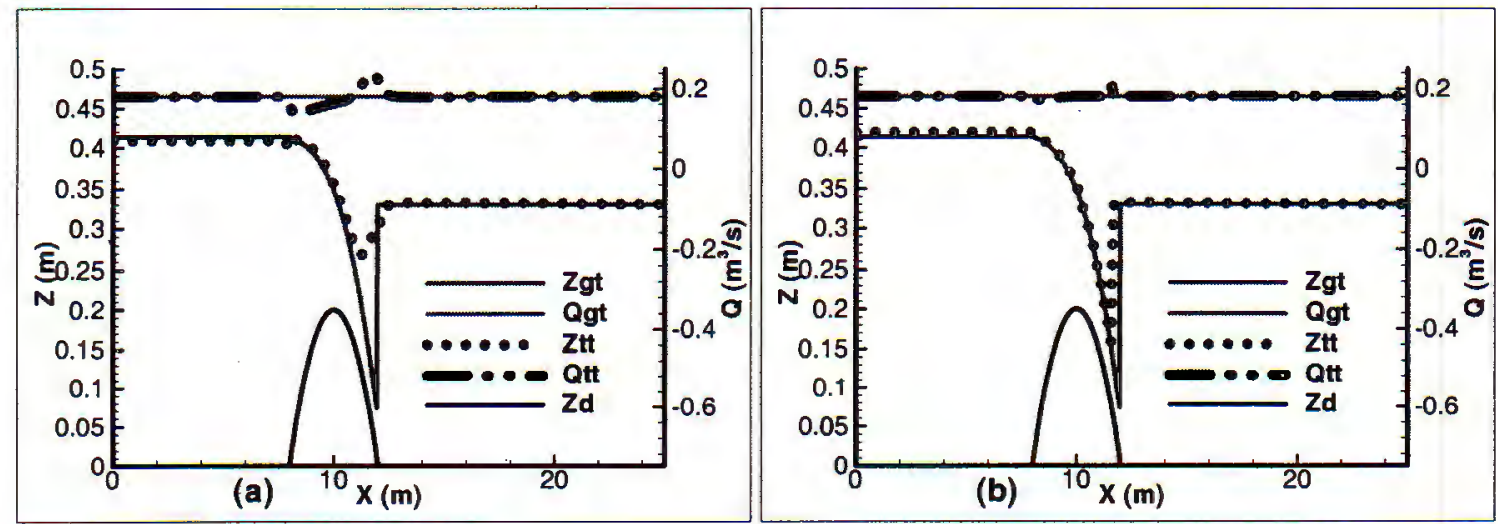

Fig. 3. Transcritical flow with shock.

(a) The Lax-Friedrichs and (b) the Roe's approximation methods

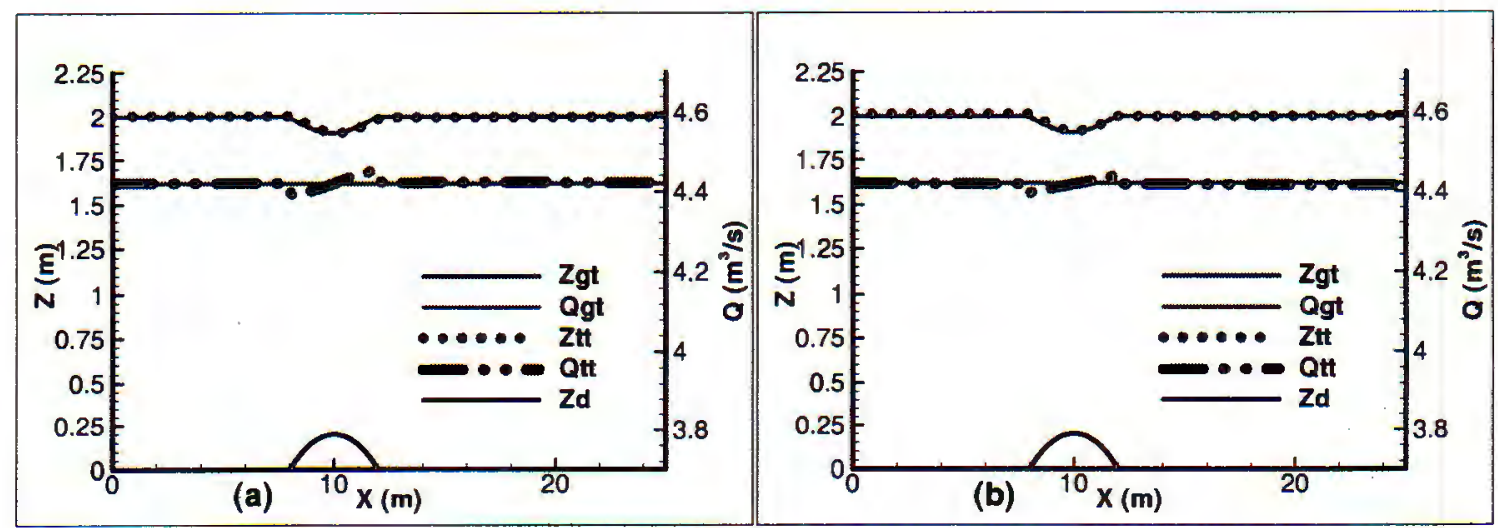

Fig. 4. The subcritical flow. (a) The Lax-Friedrichs and (b) the Roe's approximation methods 


\subsubsection{The wet bed dambreak problem}

In this case, 4 schemes are applied to calculate the unsteady flow in a flat rectangular channel for the simultaneously dambreak situation. The friction is neglected. A front wave is formulated by the gravitational force. The analytical solution is the Stocker solution that consists of a shock wave, propagated downstream and a rarefaction wave, propagated upstream [4].

The channel has a length of $2000 \mathrm{~m}$, a width of $1 \mathrm{~m}$. The dam is located on the middle of the channel. The upstream and downstream water levels of the dam are $6 \mathrm{~m}$ and $2 \mathrm{~m}$. Water is at rest at the initial time. The results at moments $100 \mathrm{~s}$ and $200 \mathrm{~s}$ are compared with the analytical solution. The comparison shows that the Roe's approximation and the hybrid methods give a solution, closed to the analytical solution better than the Nessyahu-Tedmor and the Lax-Friedrichs methods. The Lax-Friedrichs method smears the solution a lot. The Preissman method even smears the shock more than the Lax-Friedrichs method due to large numerical viscosity. Figures 5 and 6 illustrate the results of the Roe's approximation and the Preissmann methods

\subsubsection{The dry bed dambreak problem}

This test has the same condition as the wet bed dambreak problem, apart from the downstream region of the dam is dry, and is used to verify the schemes for the dambreak problem and investigate their behavior at the dry front of the wave. The analytical solution is the Ritter solution [5]. In the calculation the downstream water level is taken by $0.0001 \mathrm{~m}$.

The conclusion in this case is almost the same as in the above case. However, the Roe's approximation makes the tail of the wave more smeared with respect to the Nessyahu-Tadmor method, but has kept the necessary sharpness. The other methods seem to give the reasonable results.

Figure 7 illustrates the result for the Roe's approximation method.

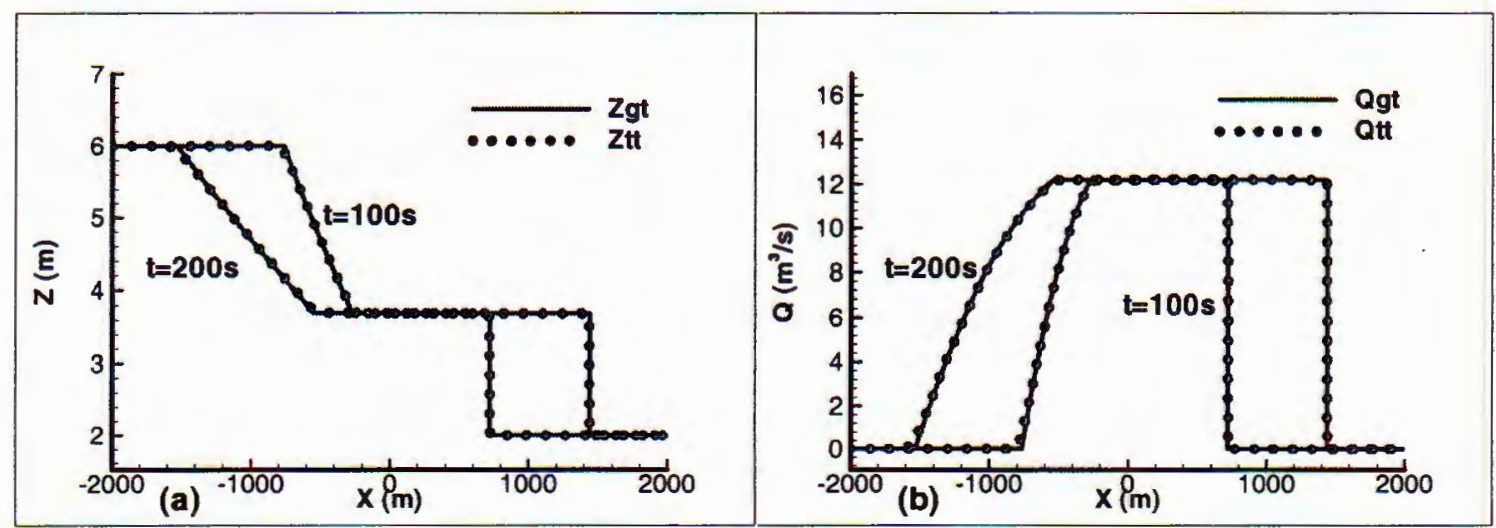

Fig. 5. The wet bed dambreak problem. The Roe's approximation method.

(a) Water levels, (b) discharges 

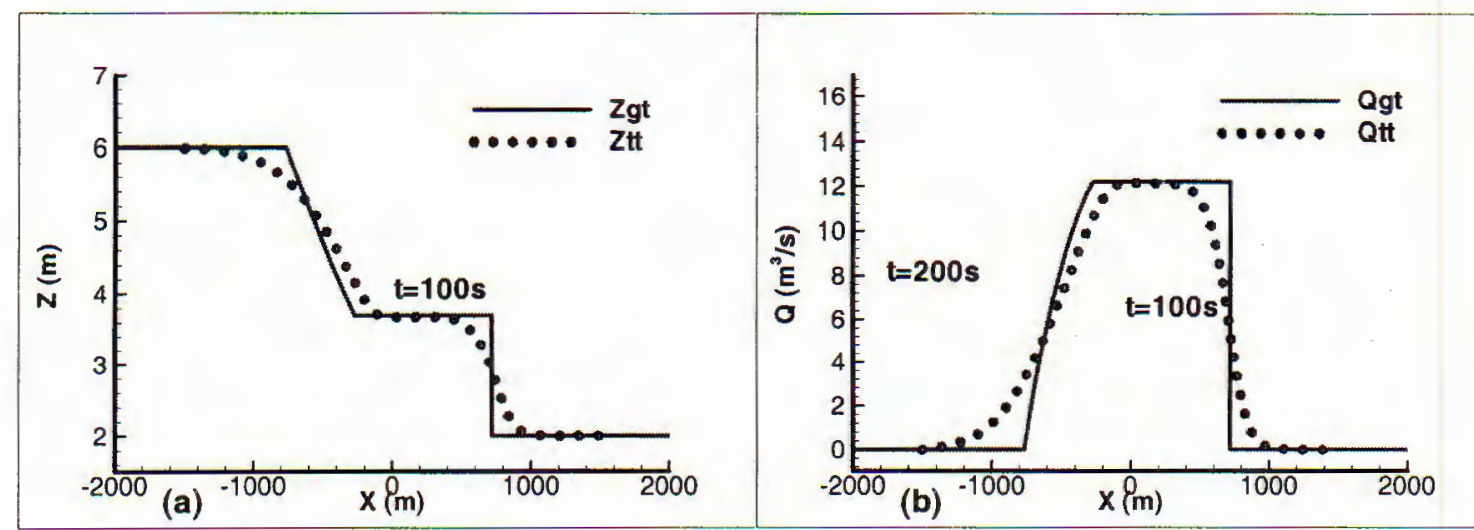

Fig. 6. The wet bed dambreak problem. The Preissman method.

(a) Water levels, (b) discharges

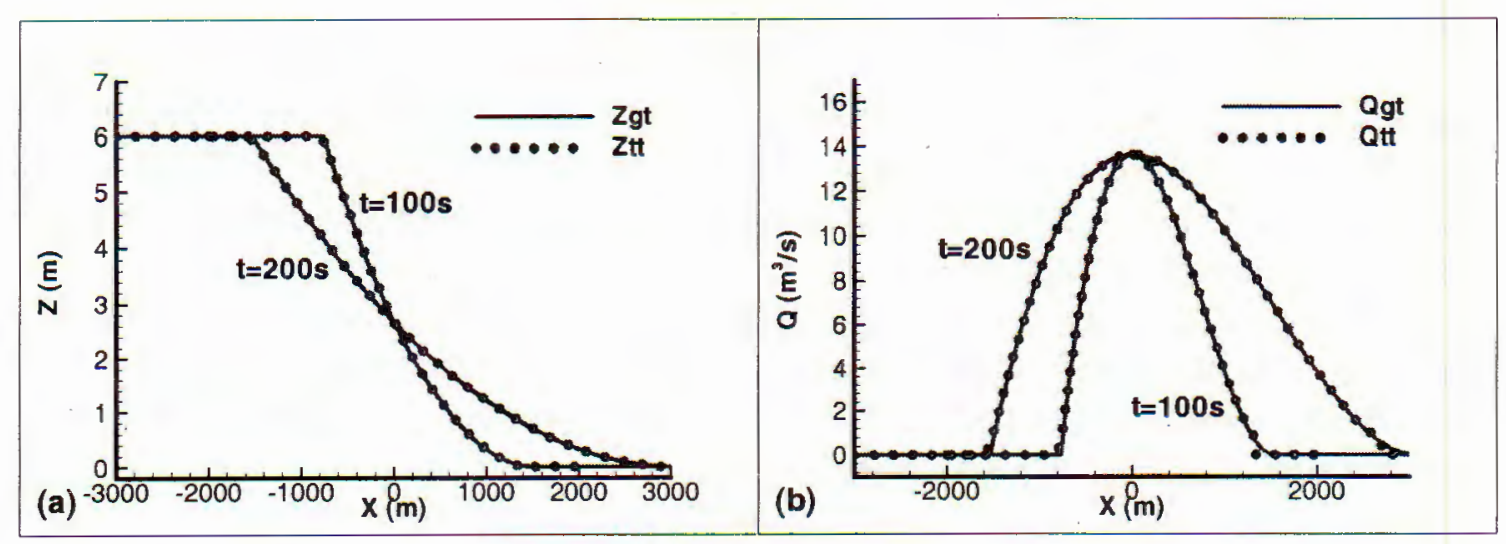

Fig. 7. The dry bed dambreak problem. Water levels. The Roe's approximation method

\section{I.1.4. The dry bed dambreak problem with friction}

The aim and conditions of this test are the same as in the above case. The difference is that the friction is taken into account with the Chezy coefficient of $40 \mathrm{~m}^{1 / 2} / \mathrm{s}$. The analytical solution is the Dressler solution [6]. The results show that the methods approximate well the Dressler solution.

Figure 8 illustrates the result for the Roe's approximation method at time moments of $40 \mathrm{~s}$.

With the splitting technique where the source term integral is evaluated according to the pointwise approach, the results are good for the rectangular channel with the constant width. In general case, when the channel has the variable bed level and width, they become much worst with the oscillation at the nonsmooth part of the solution. 


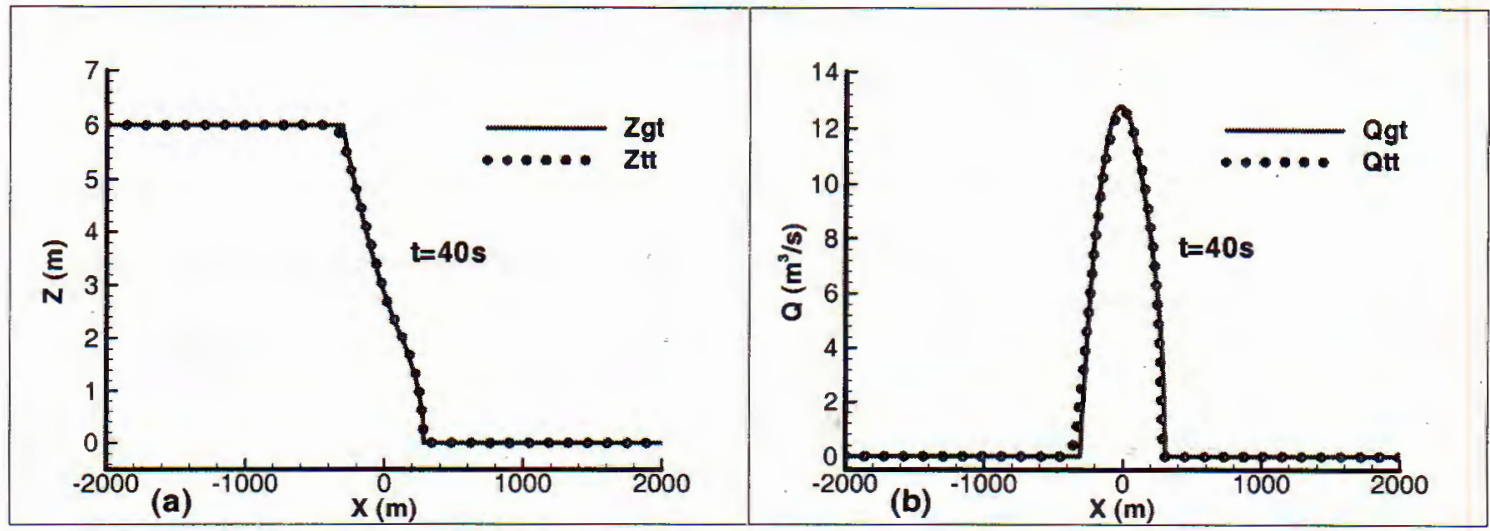

Fig. 8. The dry bed dam break problem. The Roe's approximation method.

(a) Water levels, (b) Discharges

\subsection{Roe's approximation with the mixed technique for the source terms}

In this paragraph only the Roe's approximation with the mixed technique for the source terms will be used for testing.

\subsubsection{The water at rest problem}

This test is used to verify the discretization of the source term in case of water at rest. The calculation is done for the rectangular channel of $1500 \mathrm{~m}$ length, and the variation of bed levels and widths are shown in figure 9 .

The upstream boundary condition is $Q=0 \mathrm{~m}^{3} / \mathrm{s}$ and the downstream condition is $H=12 \mathrm{~m}$. Water is at rest initially. The result (Figure $9 \mathrm{~b}$ ) shows that the numerical solution coincides with the analytical one.

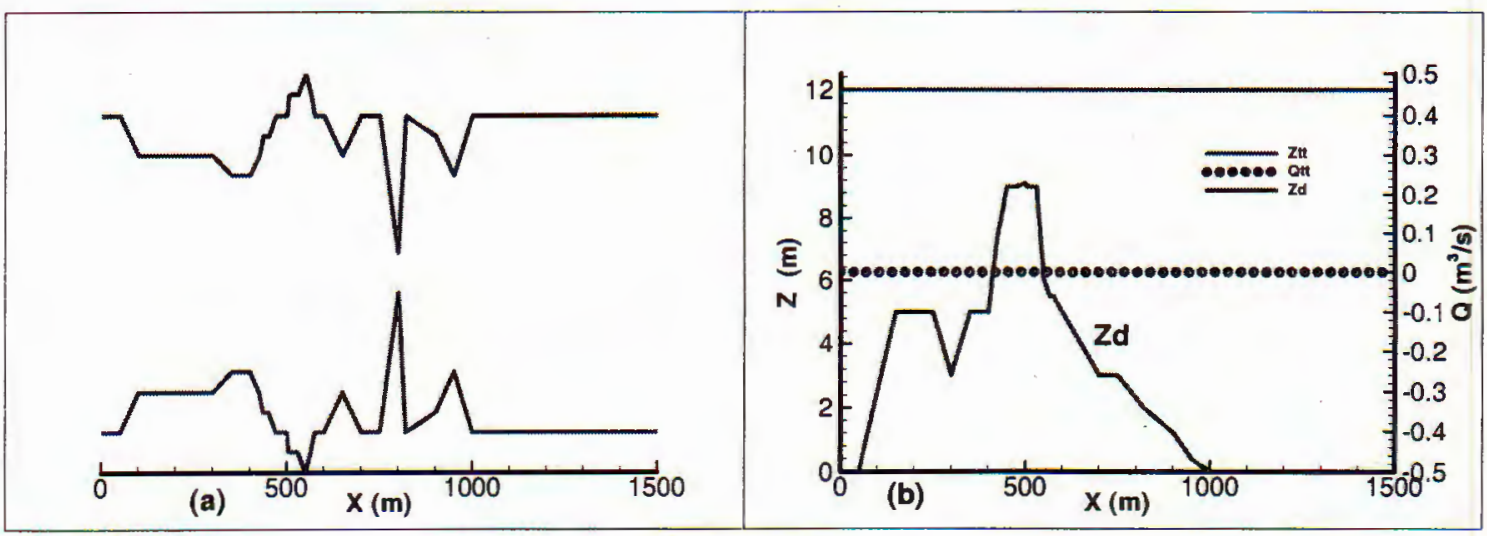

Fig. 9. The Water at rest problem.

(a) The channel width, (b) Bed and Water levels and discharge 


\subsubsection{Steady flow through a bump}

The description of this test is given above. In all cases numerical solutions approximate the analytical solution better in comparison with the pointwise source term approach. Figure 10 and Figure 11 illustrate the result.

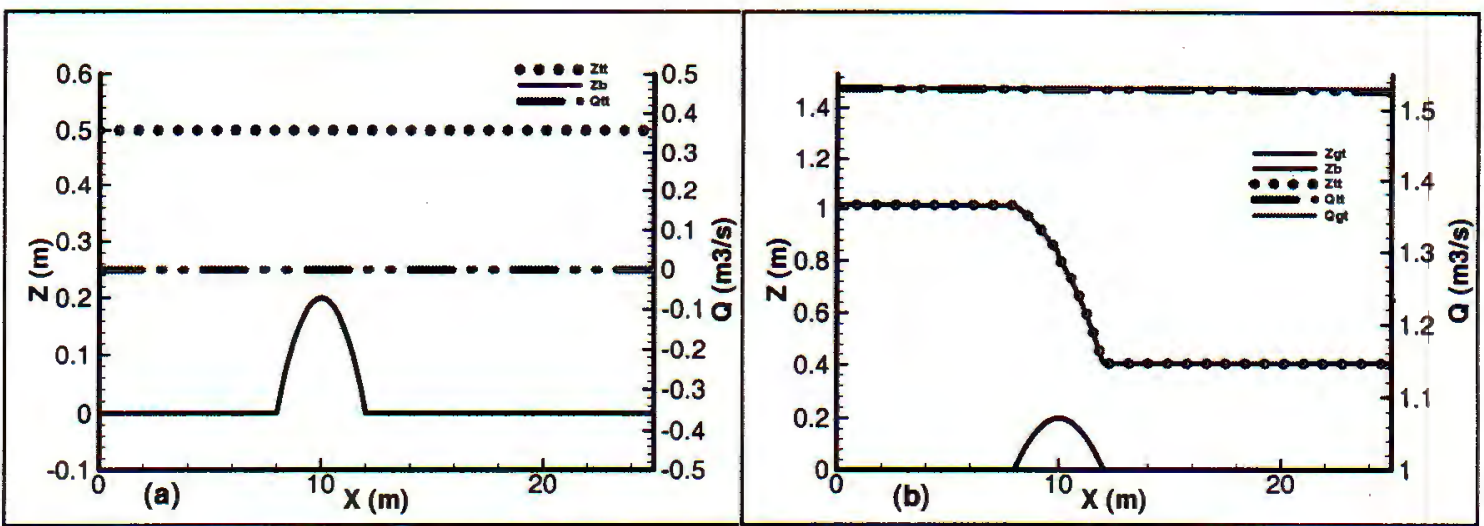

Fig. 10. (a) The water at rest case. (b) Transcritical flow without shock
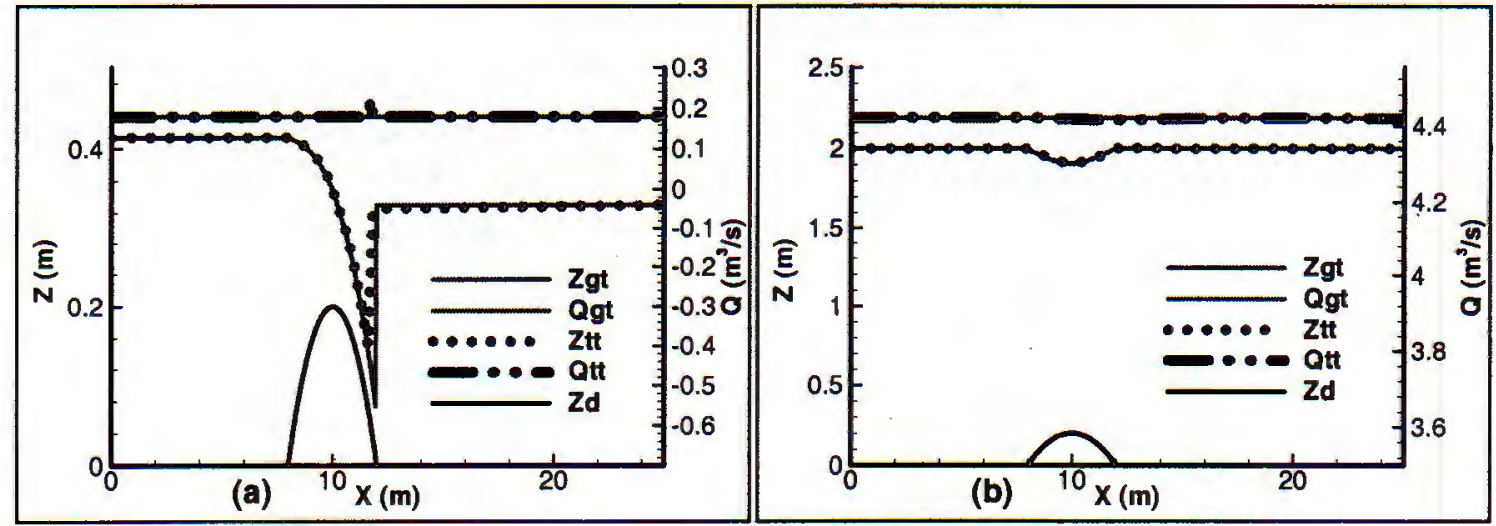

Fig. 11. (a) Transcritical flow with shock. (b) The subcritical flow

\subsubsection{The dry bed dambreak problem}

The description of this test is given above. The result (Figure 12) shows that the numerical solutions approximate well the analytical one.

\subsubsection{The wet bed dambreak problem}

The description of this test is given above. The result (Figure 13) shows that the numerical solution coincides with the analytical one.

\subsubsection{The dry bed dambreak problem with friction}

The description of this test is given above. The result (Figure 14) shows that the numerical solution gives a good approximation to the analytical one. 


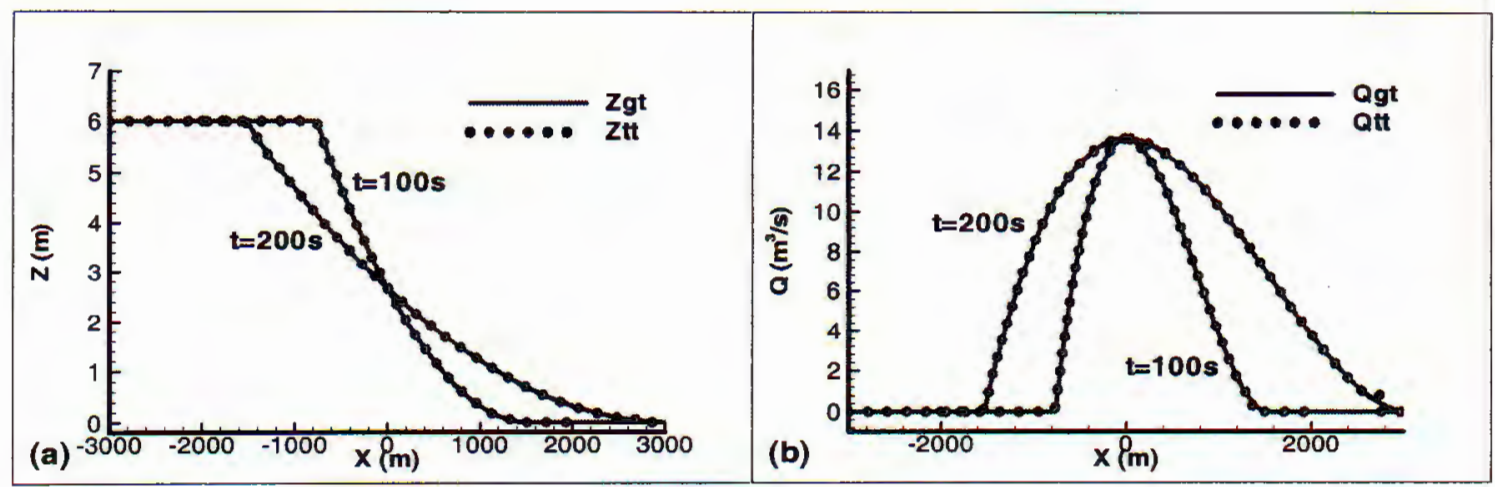

Fig. 12. The dry bed dambreak problem. (a) Water levels, (b) Discharges

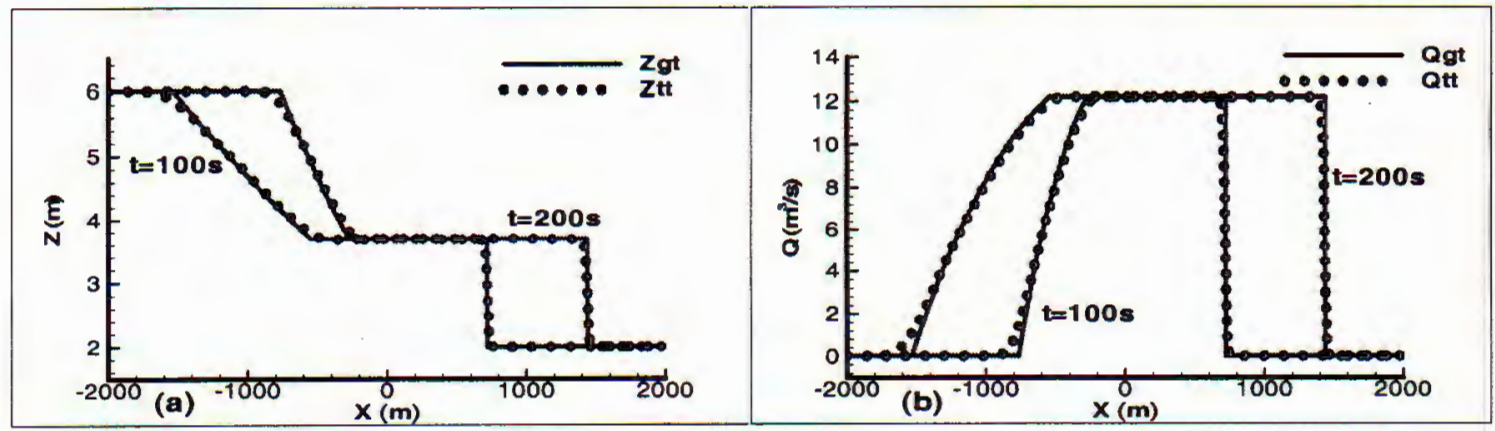

Fig. 13. The wet bed dambreak problem. (a) Water levels, (b) Discharges

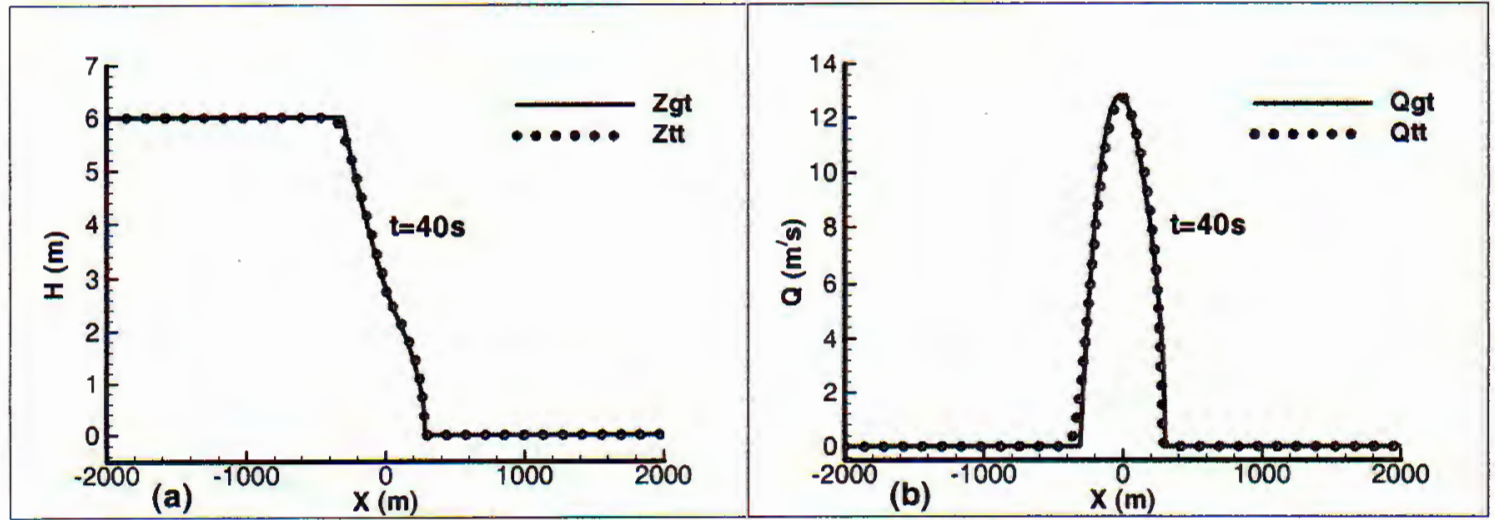

Fig. 14. The dry bed dambreak problem with friction. (a) Water levels, (b) Discharges

\subsubsection{The dambreak problem with a local constriction}

This test is constructed by one experiment in the CADAM project. In this case, 
the channel has a constriction at the downstream of the dam. The dam is simulated as a gate. The dam break wave is produced by the simultaneously opening the gate. A part of wave is reflected at the constriction and therefore the wave suffers from attenuation in propagation downstream. Due to the abrupt of the front wave and the different flow regimes this test is very appropriated for verifying the schemes, both for one and two dimensional problems. The constriction has a width of $0.1 \mathrm{~m}$. The channel is $0.5 \mathrm{~m}$ wide and its geometry is given in figure 15 .

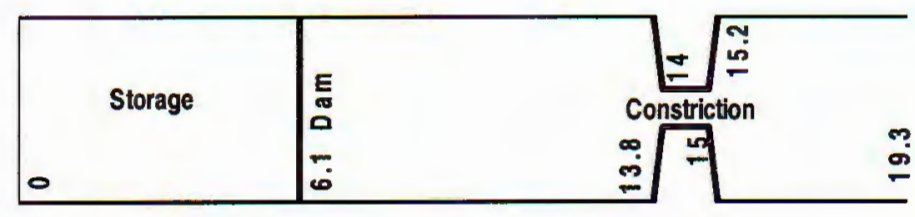

Fig. 15. The Channel geometry

At the initial time the storage has a depth of $0.3 \mathrm{~m}$, the downstream water level is $0.003 \mathrm{~m}$. The downstream boundary condition is a chute and the Strickler coefficient is $100 \mathrm{~m}^{1 / 3} / \mathrm{s}$.

The calculated results are compared with the experimental data at 4 location $x=5.1 \mathrm{~m}, 12.20 \mathrm{~m}, 14.70 \mathrm{~m}, 16.60 \mathrm{~m}$ and are illustrated in figures $16-17$. It can be shown that the obtained numerical solution approximates to the analytical one and also to the result of the MASCARET model (of France) [7].

Gauge 1 (G1) shows the propagation of the rarefaction wave in the reservoir. This wave is correctly approximated. On the second gauge (G2), we remark on the propagation with a negative velocity of a jump due to the constriction. The approximated solution models this discontinuity well. In addition, it is noticed that the time propagation (gauges 3 and 4 ) is well computed which is essential for dambreak wave simulation.

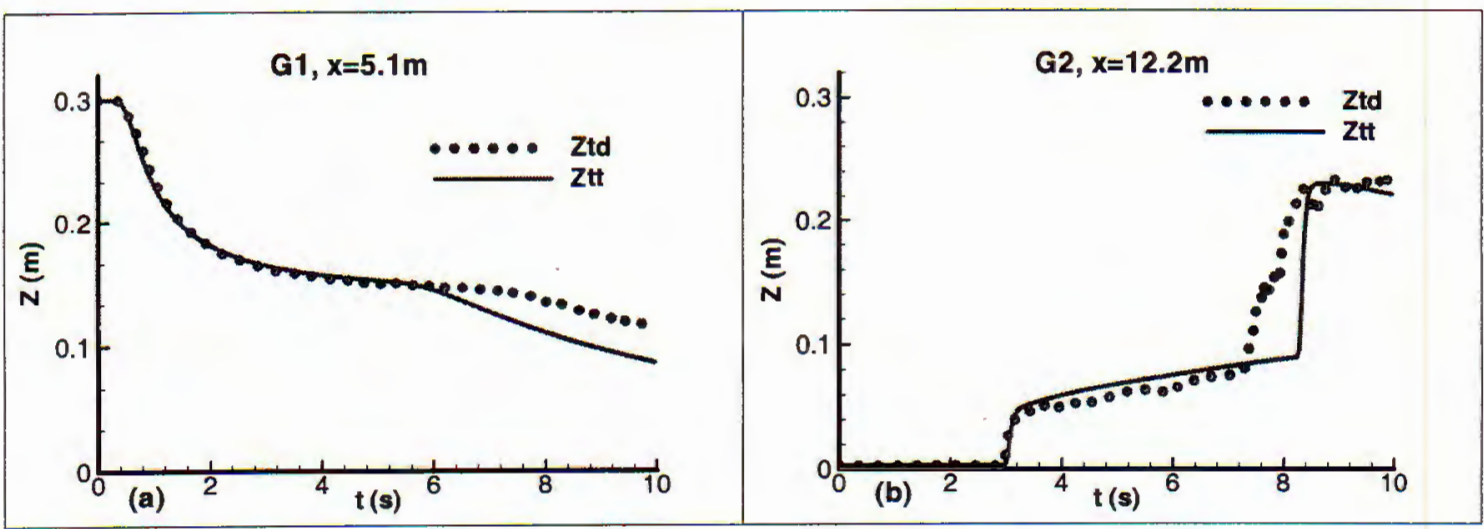

Fig. 16. The dambreak problem with a local constriction. (a) $x=5.1 \mathrm{~m}$, (b) $x=12.2 \mathrm{~m}$ $Z_{t d}$ - measurements, $Z_{t t}$ - numerical solution 


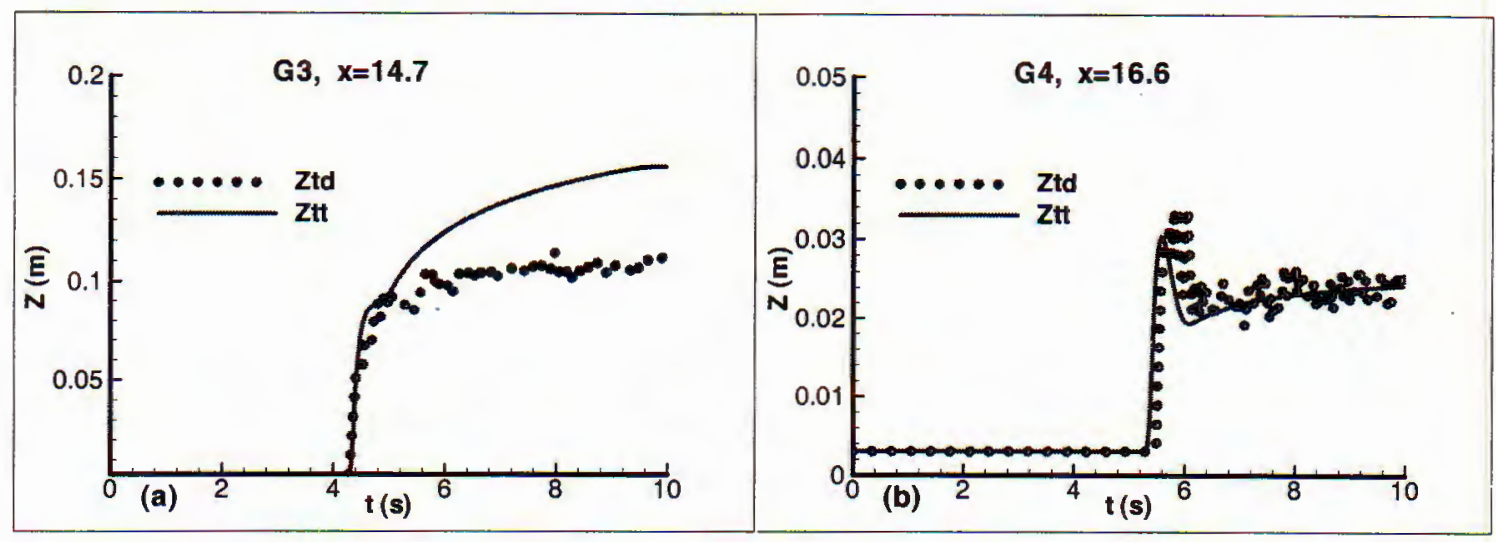

Fig. 17. The dambreak problem with a local constriction. (a) $x=12.2 \mathrm{~m}$, (b) $x=16.6 \mathrm{~m}$ $Z_{t d}$ - measurements, $Z_{t t}$ - numerical solution

\subsubsection{The hydrodynamic wave problem}

This test is described in [8] and is a test for the subcritical case. The result here is appropriated with the result, presented in [8] (Figure 18)

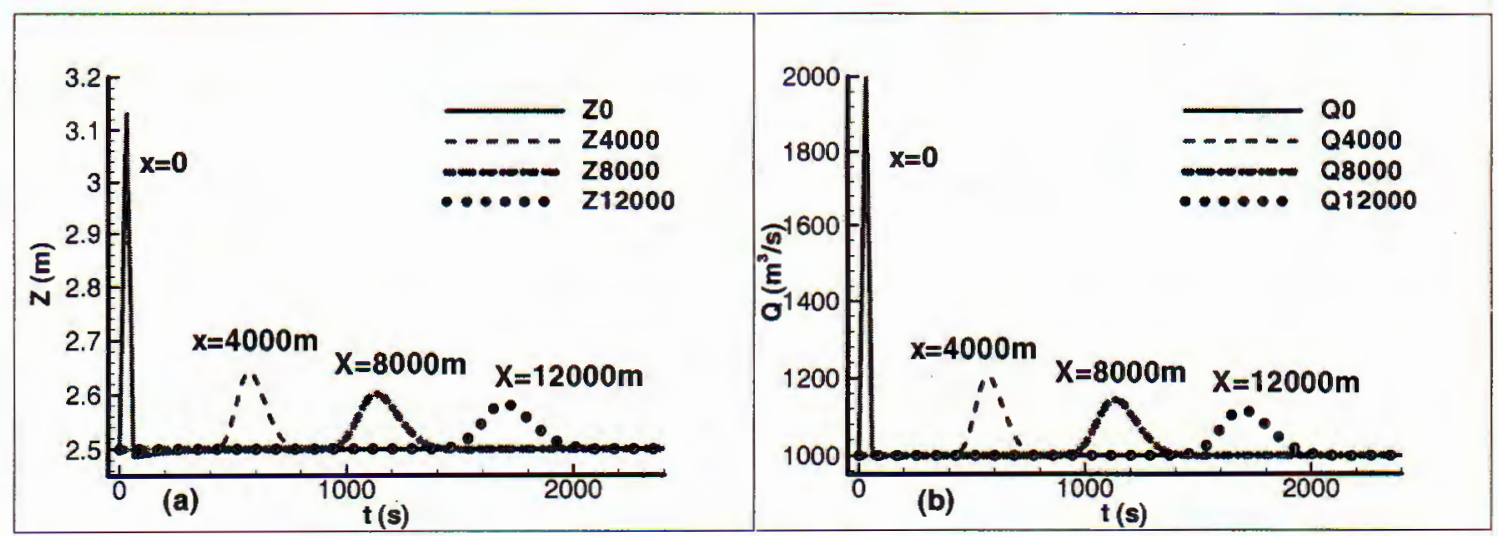

Fig. 18. The hydrodynamic wave. (a) Water depths, (b) Discharges

\subsubsection{The diffusion wave problem}

This test is described in [8] and is a test for the subcritical case also. The result here is coincided with the result, presented in [8] (Figure 19)

\subsubsection{The dynamic wave problem}

This test is used to verify schemes when the channel has the enough high bed slope, where the gravitational and friction forces are dominated. The channel is rectangular with a length of $10,000 \mathrm{~m}$, a bed slope of 0.005 and the Strickler coefficient is $31 \mathrm{~m}^{1 / 3} / \mathrm{s}$.

The initial condition is the uniform flow with the downstream water depth of $2.49 \mathrm{~m}$ and the upstream discharge of $1000 \mathrm{~m}^{3} / \mathrm{s}$. The boundary condition is given as 
for the hydrodynamic wave with $T=12$ hours, $Q_{\max }=2000 \mathrm{~m}^{3} / \mathrm{s}, T_{\max }=129000 \mathrm{~s}$. The flow pattern is correct and is illustrated in figure 20.

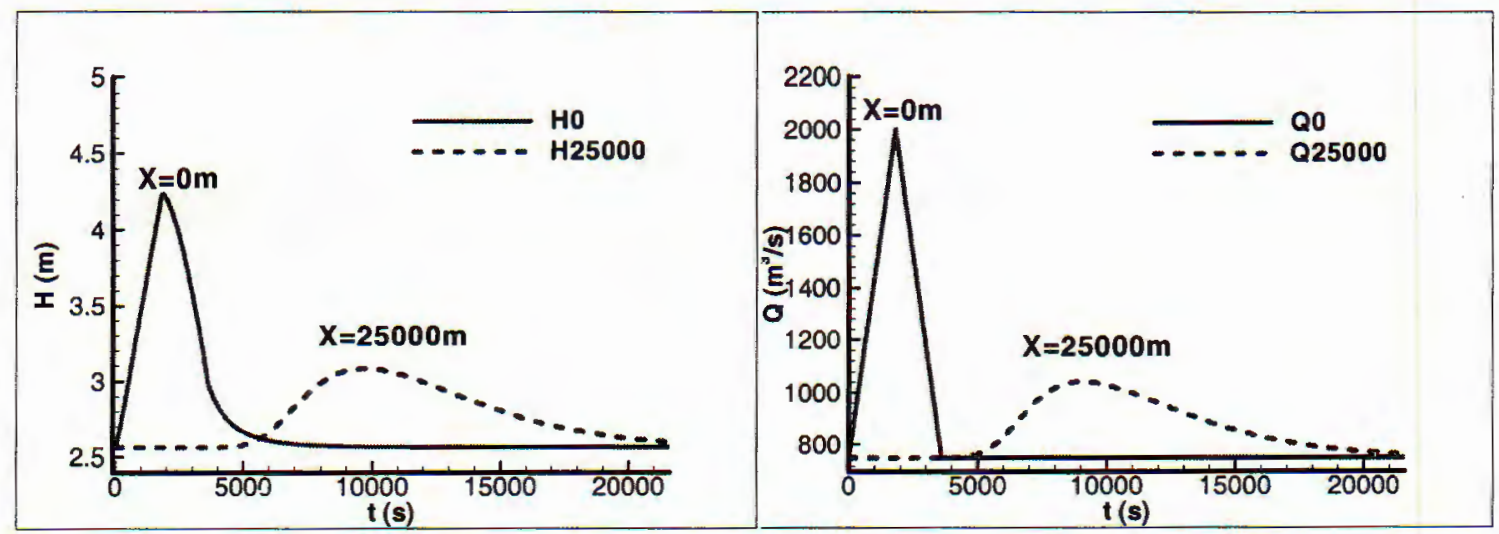

Fig. 19. The dispersion wave. Water depths and Discharges at $x=0 \mathrm{~m}$ and $x=25000 \mathrm{~m}$

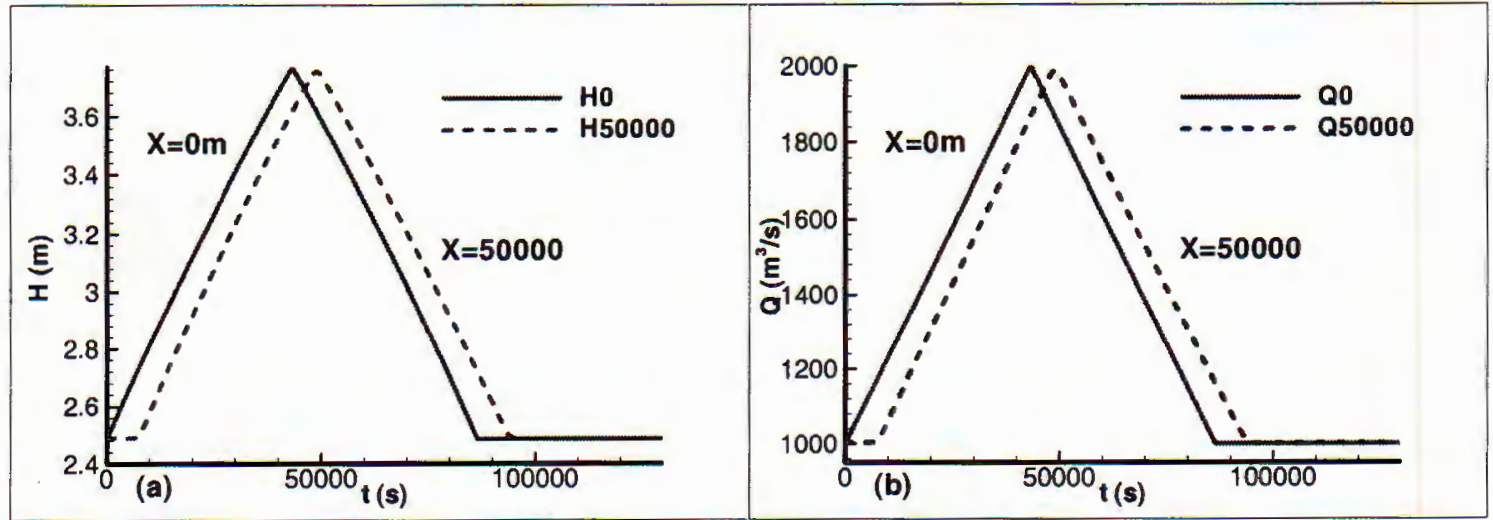

Fig. 20. The dynamic wave. (a) Water levels, (b) Discharges at $x=0 \mathrm{~m}$ and $x=50000 \mathrm{~m}$

\section{Preliminary evaluation of the Sonla-HoaBinh dambreak problem}

In this section, the Roe's approximation with the mixed technique for the source terms will be used to carry out a preliminary evaluation of the Sonla-Hoabinh dambreak problem.

Let us consider the river branch from the Vietnamese Chinese border to the Thao-Da confluence with a length of $570 \mathrm{~km}$. The future Sonla dam is located at the Pa Vinh, which is $268 \mathrm{~km}$ far from Thao-da confluence. The Hoa Binh dam is located at $63 \mathrm{~km}$ from Thao-Da confluence.

The initial water levels at the up- and downstream parts of the Hoa Binh dam 
are $125 \mathrm{~m}$ and $14 \mathrm{~m}$, at the upstream part of the Sonla dam- change from 265 to $320 \mathrm{~m}$. The upstream boundary condition is $3000 \mathrm{~m}^{3} / \mathrm{s}$ and the downstream one is a discharge-water level relation.

Dams are supposed to be simultaneously broken at time $t=0$. The result shows that the maximum discharges through the Hoabinh dam and the Sonla dam are reached after approximately $200 \mathrm{~s}$. The shock travel time from Hoa Binh to Thao-Da confluence is approximately 1,5 hour.

This flow pattern is correct for the simultaneously dam-break wave and the result is approximately closed the result of the research project for the Son La dam break of the Institute of Mechanics.

\section{Conclusion}

In this part of the paper, the verification of 4 numerical methods for solving the Saint-Venant equations: the Lax-Friedrichs, the Self-adjusting Hybrid, the Nessyahu-Tedmor, and the Roe's approximation methods, are presented. The source terms can be discretized following the pointwise, upwind or mixed approaches. By the numerical tests it is recommended that upwind and the mixed approaches are more appropriated to the Saint-Venant equations, the Roe's approximation is an efficient method and can be used with all the source term approaches of discretization.

The numerical tests are carried out for all flow regimes: sub-, super- and transcritical flow. Then the Roe's approximation with the upwind and mixed technique for the source terms is used for a preliminary evaluation of the Son La - Hoa Binh dambreak problem.

This publication is completed with finalcial support from the Decision Support System for Ecosystem Upgrading and Flood Control of a Sustainable Development in the Red River System Project and the National Basic Research Program in Natural Sciences, Ministry of Science, Technology and Environment.

\section{REFERENCES}

1. Nguyen Van Hanh, Nguyen Van Diep and Ngo Huy Can, On some methods for solving the 1-D Saint-Venant Equations of general flow regime. Part 1: Numerical methods, Vietnam J. of Mech. Vol. 24 2002, Num 4, 236-248.

2. CADAM Final report. Test cases 3.

3. A Le Bosse, Codes de Calcul d'ecoulement a surface libre filaire "LIDO", "SARA", et "REZO" (version 2.0). Note de validation, EDF, 1993.

4. Stocker J. J. Water Waves: The Mathematical Theory with Applications, Interscience Publishers Inc. New York 1957 
5. Ritter A. Die Fortplanzung der wasserwellen, Z. Verdeut Ing. 36, 1892.

6. Dressler R. F. Hydraulic resitance efect upon the Dam-Break Functions, National Bureau of Standards, Journal of Research, Vol 19, N3, 1952.

7. Goutal N. and Maurel F. A finite volume solver for 1D shallow-water equations applied to an actual river, Int. J. Numer. Meth. Fluids 38, p 1-19, 2002.

8. Nguyen Van Hanh, Ngo Huy Can, Nguyen Van Diep. On a one- and quasi-two dimensional linking hydraulic model for the complex river network- Validation and Application, Vietnam J. of Mech. Vol. 24, Num. 3, p181-196, 2002.

Received September 12, 2002

\section{VỀ MỘT SỐ PHƯONG PHÁP GIẢI SỐ HỆ PHƯONG TRİNH SAINT-VENANT MỘT CHIỀU TRONG CHẾ ĐỘ DÒNG CHẢY TÔNNG QUÁT. PHẦN 2: KIỂM ĐỊNH VÀ ỨNG DỤNG}

Phần 1 của bài báo [1] đã trình bày một số phương pháp giải số hệ phương trình Saint-Venant một chiều trong chế độ dòng cháy tổng quát, khi dòng chảy có thể là hỗn hợp giữa chảy êm và chảy xiết. Phần 2 của bài báo giới thiệu kết quả kiểm tra bằng một loạt các bài toán mẫu, bao hàm cá 3 chế độ dòng chảy: êm, xiết, chuyển ngưỡng. Các kết quà cho thấy việc xử lý thành phần nguồn hỗn hợp tốt hơn so với cách xử lý theo dạng điểm, và biến đổi thành phần nguồn cần phải hết sức thận trọng vì nó có thể dẫn đến lời giải số không vật lý. Phương pháp xấp xỉ Roe với cách xử lý hỗn hợp thành phần nguồn sau đó được áp dụng đánh giá thử nghiệm bài toán vỡ đập các đập Sơn La và Hòa Bình. 